\title{
Low affinity PEGylated hemoglobin from Trematomus bernacchii, a model for hemoglobin- based blood substitutes
}

\author{
Daniela Coppola ${ }^{1}$, Stefano Bruno ${ }^{2 *}$, Luca Ronda ${ }^{2}$, Cristiano Viappiani ${ }^{3}$, Stefania Abbruzzetti ${ }^{3,4}$, Guido di Prisco ${ }^{1}$, \\ Cinzia Verde ${ }^{1}$ and Andrea Mozzarelli ${ }^{2}$
}

\begin{abstract}
Background: Conjugation of human and animal hemoglobins with polyethylene glycol has been widely explored as a means to develop blood substitutes, a novel pharmaceutical class to be used in surgery or emergency medicine. However, PEGylation of human hemoglobin led to products with significantly different oxygen binding properties with respect to the unmodified tetramer and high NO dioxygenase reactivity, known causes of toxicity. These recent findings call for the biotechnological development of stable, low-affinity PEGylated hemoglobins with low NO dioxygenase reactivity.

Results: To investigate the effects of PEGylation on protein structure and function, we compared the PEGylation products of human hemoglobin and Trematomus bernacchii hemoglobin, a natural variant endowed with a remarkably low oxygen affinity and high tetramer stability. We show that extension arm facilitated PEGylation chemistry based on the reaction of T. bernacchii hemoglobin with 2-iminothiolane and maleimido-functionalyzed polyethylene glycol (MW 5000 Da) leads to a tetraPEGylated product, more homogeneous than the corresponding derivative of human hemoglobin. PEGylated T. bernacchii hemoglobin largely retains the low affinity of the unmodified tetramer, with a p50 50 times higher than PEGylated human hemoglobin. Moreover, it is still sensitive to protons and the allosteric effector ATP, indicating the retention of allosteric regulation. It is also 10-fold less reactive towards nitrogen monoxide than PEGylated human hemoglobin.
\end{abstract}

Conclusions: These results indicate that PEGylated hemoglobins, provided that a suitable starting hemoglobin variant is chosen, can cover a wide range of oxygen-binding properties, potentially meeting the functional requirements of blood substitutes in terms of oxygen affinity, tetramer stability and NO dioxygenase reactivity.

\section{Background}

Hemoglobin-based oxygen carriers (HBOCs) are a novel therapeutic class consisting of hemoglobin $(\mathrm{Hb})$ derivatives administered intravenously as substitutes for blood transfusions. Modifications of the natural tetramer are required to reduce toxicity, as unmodified, cell-free $\mathrm{Hb}$, once dissociated into dimers, is easily filtered by the kidneys and causes severe nephrotoxicity. Moreover, $\mathrm{Hb}$ extravasates through the endothelium, where it scavenges the vasoactive mediator nitrogen monoxide $(\mathrm{NO})$, causing a range of toxic effects that include

\footnotetext{
* Correspondence: stefano.bruno@unipr.it

${ }^{2}$ Department of Biochemistry and Molecular Biology, University of Parma, Parma, Italy

Full list of author information is available at the end of the article
}

vasoconstriction and blood pressure increase. The strategies so far explored to avoid such effects mainly aim at increasing the molecular size of the natural $\mathrm{Hb}$ tetramers, thus limiting the size-dependent vessel extravasation and renal ultrafiltration. Beside some attempts at designing recombinant $\mathrm{Hbs}$ with higher molecular weight or lower dimer-tetramer dissociation constants [1-5], most products proposed for clinical use consist of $\mathrm{Hb}$ purified from whole blood and chemically modified to achieve either intramolecular cross-linking or conjugation with polyethylene glycol (PEG) [6]. PEG derivatization usually consists in the reaction between maleimido-functionalized PEG (MAL-PEG) molecules with either solvent-exposed cysteyl residues or thiol groups introduced through the reaction of lysyl side

\section{Biomed Central}


chains with 2-iminothiolane (IMT) under either aerobic [7] or anaerobic [8] conditions. PEG-decorated human $\mathrm{Hb}$ (HbA) derivatives have been evaluated in several clinical trials [9]. Adverse effects have so far prevented their application as a replacement of red blood cells [10].

One of the limits of HBOCs lies in the large differences between their oxygen binding properties with those of red blood cells. As a matter of fact, cell-free HbA cannot bind the intra-erythrocyte allosteric effector 2,3-bisphosphoglycerate, which increases the $P_{50}$ (the oxygen partial pressure required to achieve half saturation) from 10 Torr to around 26 Torr at $37^{\circ} \mathrm{C}, \mathrm{pH} 7.4$. Moreover, free $\mathrm{Hb}$ in the plasma is usually at concentrations low enough to significantly dissociate into dimers, which do not show cooperativity and exhibit a $P_{50}$ close to that of R-state $\mathrm{Hb}$. PEGylation itself destabilizes the $\mathrm{Hb}$ tetramer and shifts the tetramer-dimer equilibrium towards the latter, with loss of cooperativity and a further increase in affinity [11]. Particularly, the reaction of PEG with Cys $\beta 93$, conserved in $90 \%$ of vertebrates [12], was associated with tetramer dissociation and increased affinity [11,13]. As a matter of fact, both PEGylation of $\mathrm{HbA}$ in the T quaternary state, where Cys $\beta 93$ is not reactive [8] and the reversible protection of Cys $\beta 93 \mathrm{HbA}$ prior to conjugation [14] result in higher tetramer stability and lower affinity. However, based on experiments on HbA mutants, an increase in oxygen affinity seems to be at least partially independent of the derivatization of Cys $\beta 93$ [15], suggesting that PEGylation induces changes in the hydration shell of hemoglobin, shifting the conformational equilibrium towards the more hydrated $\mathrm{R}$ state, regardless of the PEGylation sites.

In the light of the recent setbacks suffered by PEGylated $\mathrm{Hb}$ in clinical trials [10], a deeper investigation of the relationship between the oxygen-binding properties and PEGylation in Hbs was undertaken. One of the possible strategies focused on the use of non-human PEGylated Hbs, taking advantage of the low immunogenicity of PEGylated proteins in general [16]. Non-human Hbs might greatly differ in terms of PEGylation pattern, oxygen-binding properties and sensitivity to allosteric effectors. A product consisting of bovine $\mathrm{Hb}$ decorated with 10-12 units of 5000 Da-MW PEG was investigated as a possible blood substitute and showed a $P_{50}$ of 10.2 Torr at $37^{\circ} \mathrm{C}$ [17], higher than that of PEGylated human $\mathrm{Hb}$ but still far from that of human blood (around 26 Torr). TetraPEGylated canine $\mathrm{Hb}[16]$ similarly showed a $P_{50}$ of 10 Torr under the same conditions. In view of investigating the relationship between the oxygen affinity of animal Hbs and that of their PEGylation products, Hbs from Notothenioidei, the dominant suborder of teleosts in Antarctica, are particularly interesting, as they show peculiar features that make them potentially less sensitive to the undesirable effects of PEGylation. The oxygen affinity of these Hbs is exceptionally low [18], an evolutionary consequence of the high oxygen concentration in the cold Antarctic waters. Moreover, unlike HbA, fish Hbs show little or no dissociation of the tetramer into dimers, even in the ligated form [19]. Finally, Cys $\beta 93$, present in the great majority of vertebrate $\mathrm{Hbs}$ and known to greatly perturb the properties of PEGylated Hbs and to scavenge NO [11], is missing in Hbs of almost all teleosts. The remaining cysteyl residues are all buried inside the protein matrix [20], suggesting that PEG conjugation can be carried out regardless of the quaternary or ligation state. We therefore decorated $\mathrm{Hb}$ from Trematomus bernacchii $(\mathrm{Tb} \mathrm{Hb})$ with PEG and characterized the reactivity with oxygen and NO. The results were compared with those obtained for PEGylated HbA.

\section{Methods \\ Reagents}

2-iminothiolane (IMT), HEPES buffer, ethylendiaminotetraacetic acid (EDTA), phosphate buffered saline solution (PBS), sodium ascorbate, catalase and the reagents for the Hayashi enzymatic reducing system [21] were purchased from Sigma Chemical Co. (St. Louis, MO, U. S.A.) and maleimido polyethylene glycol (MAL-PEG) (5600 Da-MW) from Nektar Molecule Engineering (Nektar Therapeutics, San Carlos, CA, U.S.A.). All other reagents were of the best available commercial quality.

\section{Collection of specimens and Hbs purification}

Specimens of $T b \mathrm{Hb}$ were collected by gill nets or hookand-line in the vicinity of Terra Nova Bay "Mario Zucchelli" Station (74²'', $\left.164^{\circ} 07^{\prime} \mathrm{E}\right)$, Ross Sea, Antarctica, and kept in aquaria supplied with running, aerated sea water. Blood was withdrawn with heparinised syringes from the caudal vein. Hemolysates were prepared as described previously [22]. Saline-washed erythrocytes were frozen at $-80^{\circ} \mathrm{C}$ until use. Purification of $T b \mathrm{Hb}$ at $98 \%$ was carried out as described previously [23]. HbA was purified as described elsewhere [24].

\section{Cysteine titration}

Preliminarily to PEGylation experiments, the reactivity of the cysteyl residues of $T b \mathrm{Hb}$ was evaluated in both the deoxy- (T) and carboxy- (R) states using 4,4'dithiodipyridine (4-PDS) [25]. For the titration under anerobic conditions, the protein solution was incubated under helium flux until the absorption spectrum shifted to the deoxy-Hb form. A separately deoxygenated stock solution of 4-PDS was anaerobically added.

\section{Hbs PEGylation}

The PEGylation reaction was carried out following the protocol published for $\mathrm{HbA}$ in aerobic conditions 
$[11,26]$. Briefly, $T b \mathrm{Hb}$ or $\mathrm{HbA}$ were treated in the presence of IMT ( 80 moles/tetramer moles) and then with MAL-PEG 5600 Da-MW (12 moles/tetramer moles) (Figure 1 ), at $10^{\circ} \mathrm{C}$ to prevent any heme oxidation during the reaction. $\mathrm{TbHb}$ was treated in the presence of $\mathrm{CO}$, subsequently removed under oxygen flow before measurements. The reactions of IMT and MAL-PEG were quenched using lysine and cysteine in excess, respectively. Less than $5 \%$ met-Hb was formed during the reaction. To monitor the PEGylation reaction, small aliquots of the reaction mixture were sampled every 10 minutes. The reaction was quenched by addition of lysine and cysteine in excess. The samples were analyzed by sodium dodecylsulfate/polyacrylamide gel electrophoresis (SDS-PAGE) and the electropherograms were evaluated using the Quantity One software (Bio-Rad). Under denaturing conditions, SDS-PAGE applied to PEGylated $\mathrm{Hbs}$ was able to separate PEGylated $\mathrm{Hb}$ into unmodified globin chains and globin chains with different PEGylation degree [11]. To evaluate the

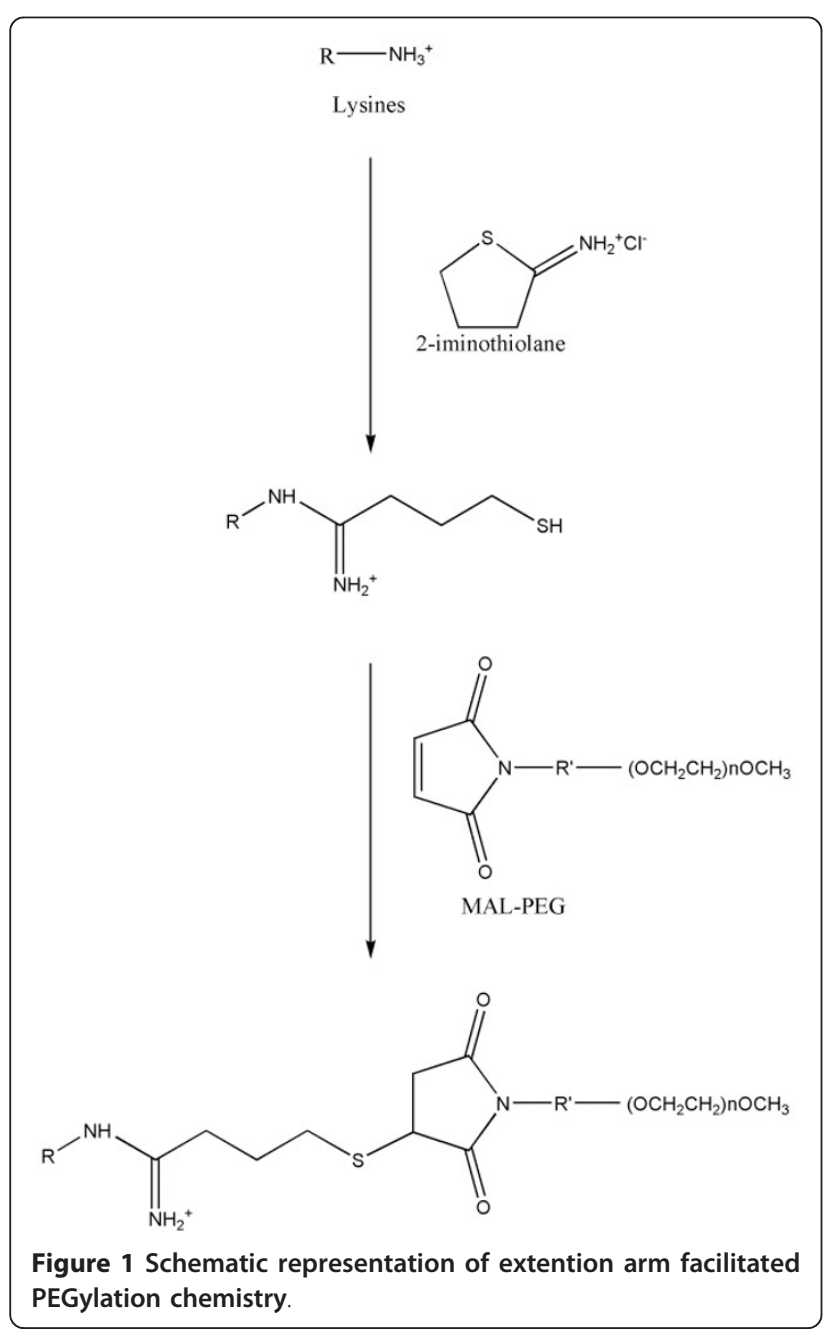

homogeneity of the final products, electrophoresis under native conditions was carried out in $8-2 \%$ gradient gel and analyzed as described elsewhere [27].

\section{Determination of oxygen-binding curves}

Oxygen-binding curves of $\mathrm{HbA}, T b \mathrm{Hb}$ and their PEGylated derivatives, called PEG- $\mathrm{Hb}^{\text {oxy }}$ and PEGTbHb, respectively, were measured with a modified tonometer [24]. Before titration, the stock solutions of the proteins were diluted in a solution containing $100 \mathrm{mM}$ HEPES, 1 mM sodium EDTA, at either $\mathrm{pH} 7.0$ or 8.0 , to a final concentration of $30 \mu \mathrm{M}$. Sodium ascorbate and catalase were added to final concentrations of $5 \mathrm{mM}$ and $10^{3} \mathrm{U} /$ $\mathrm{ml}$, respectively, to prevent significant autoxidation during the measurement. For $T b \mathrm{Hb}$ and PEGTbHb, experiments were carried out in the presence and absence of the allosteric effector ATP at a final concentration of 3 $\mathrm{mM}$. For the experiments on $\mathrm{TbHb}$ and PEGTbHb stored in the carbomonoxy form, $\mathrm{CO}$ was removed by exposure to pure oxygen for 2 hours prior to titration, taking advantage of the relatively low affinity of $T b \mathrm{Hb}$ for $\mathrm{CO}$ (data not shown). The samples where then exposed to oxygen partial pressures ranging from 0 to 760 Torr generated using an Environics 4000 (Environics inc, Tolland, CT, U.S.A.) gas mixer and pre-mixed helium/oxygen bottles, at $10^{\circ} \mathrm{C}$. Spectra were collected in the 350-700 $\mathrm{nm}$ range using a Cary 4000 (Agilent Technologies, Lexington, MA, U.S.A.) spectrophotometer. The oxygen saturation at each partial oxygen pressure was determined by deconvoluting the spectra in the 450-700 $\mathrm{nm}$ range to a linear combination of the reference spectra of deoxy-, oxy- and met-Hb, plus a baseline. The deoxy reference spectra were obtained for $\mathrm{HbA}$ and $T b \mathrm{Hb}$ in the presence of sodium dithionite, whereas reference spectra for the oxy forms were obtained in pure oxygen in the presence of the Hayashi reducing system [21]. The Hill's coefficient $(\mathrm{n})$ and $P_{50}$ were calculated by linear regression of the Hill's plots in the saturation range $20-80 \%$.

\section{Flash photolysis experiments}

The experimental set up has been described previously $[28,29]$. Flash photolysis measurements were performed using the circularly polarized second harmonic of a Qswitched Nd:YAG laser (Surelite II Continuum) and a cw Xe arc lamp as a monitoring beam. The transient absorbance signals were measured at $436 \mathrm{~nm}$ with a 5stage photomultiplier.

\section{NO dioxygenase activity}

The rates of the NO dioxygenase reactivity at a single $\mathrm{NO}$ concentration were determined for $\mathrm{HbA}, \mathrm{Tb} \mathrm{Hb}$, PEG-Hb ${ }^{\text {oxy }}$ and PEGTbHb by rapid mixing using a stopped-flow apparatus (SX.18MV, Applied 
Photophysics). The NO solutions were generated by equilibrating a previously deoxygenated PBS solution at $\mathrm{pH} 7.4$ with a gas mixture of $\mathrm{NO}$ in nitrogen. The exact concentration of $\mathrm{NO}$ was then measured by titration of the solution with deoxygenated $\mathrm{HbA}$ under anaerobic conditions and determined to be $12 \mu \mathrm{M}$. The protein concentration was $3 \mu \mathrm{M}$. The reaction was monitored at $405 \mathrm{~nm}$. Between 5 and 10 traces were collected and averaged. All measurements were carried out under strict anaerobic conditions at $20^{\circ} \mathrm{C}$.

\section{Results and Discussion}

\section{Cysteine reactivity}

Sulfhydryl reactivity towards 4-PDS of carbomonoxyand deoxy- $T b \mathrm{Hb}$ was very slow (data not shown) with the fastest-reacting cysteine completing the reaction in more than 24 hours. The slow reactivity of $T b \mathrm{Hb}$ confirmed the structural data [20], which indicated the absence of exposed cysteyl residues. 2-iminothiolanegenerated $\mathrm{SH}$ groups are therefore predicted to be the only reactive sites towards MAL-PEG (Figure 1). For comparison, $\mathrm{HbA}$ reacts with a twice equimolar amount 4-PDS within 10 minutes (data not shown) due to the exposed Cys $\beta 93$. It is therefore expected that $T b \mathrm{Hb}$, unlike $\mathrm{HbA}$, would not react directly with MAL-PEG.

\section{PEGylation}

Samples collected at different times of the PEGylation reaction were compared in a SDS-PAGE gel (data not shown) and analyzed by densitometry (Figure 2). The reaction appeared to be completed in 30 minutes. The densitometric analysis [11] showed that about four PEG chains per tetramer are added during the reaction, as compared to the 5-6 PEG chains/tetramer added to $\mathrm{HbA}$ under the same reaction conditions. Nevertheless, in native electrophoresis, PEGTbHb exhibited a slower migration with respect to $\mathrm{PEG}-\mathrm{Hb}^{\text {oxy }}$, possibly due to differences in electric charge (Figure 3). Some other noticeable differences emerged with respect to PEG$\mathrm{Hb}^{\text {oxy }}$. Particularly, the $\mathrm{TbHb}$ PEGylated derivative appeared more homogeneous and did not show any traces of unmodified tetramer (Figure 3), which were consistently observed in all preparation of PEG-Hb ${ }^{\text {oxy }}$ [27]. It is widely recognized that unmodified $\mathrm{Hb}$ is very toxic, as it can extravasate and be filtered at glomerular level. The complete derivatization of $T b \mathrm{Hb}$ would therefore be a valuable property for a blood substitute.

\section{Oxygen-binding properties}

Oxygen affinity, cooperativity and the Bohr effect of PEGylated $\mathrm{Hb}$ derivatives and unmodified $\mathrm{Hbs}$ were measured under different conditions (Figure 4). The oxygen-binding curves were determined at $\mathrm{pH} 7.0$ and $\mathrm{pH} 8.0$, at $10^{\circ} \mathrm{C}$. The analysis allows calculating $P_{50}$ and

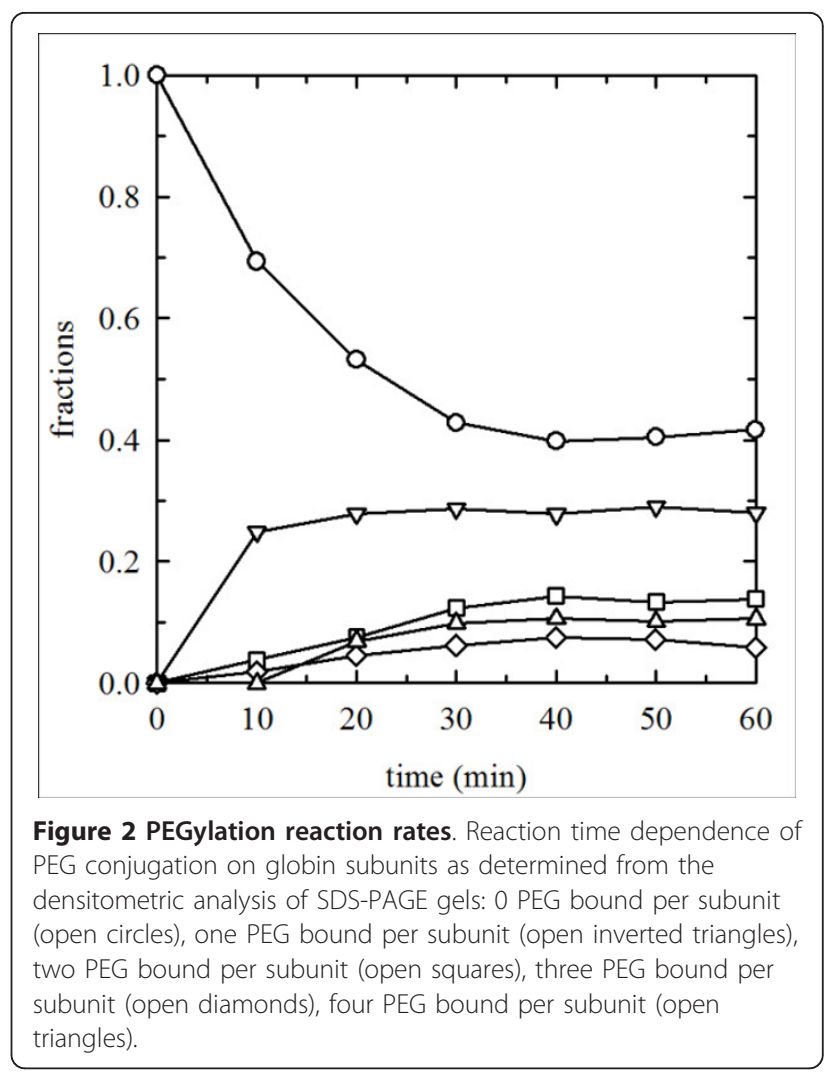

Hill coefficient values (Table 1). At pH 7.0, HbA exhibited a $P_{50}$ of 1.7 Torr, which decreased to approximately 0.4 Torr upon PEGylation (Table 1). The derivatization also resulted in loss of cooperativity, with the Hill coefficient decreasing from around 2 to 1.2 . $T b \mathrm{Hb}$, under the same conditions, showed a much higher $P_{50}$ of $28.2 \pm$ 0.2 Torr. PEGylation resulted in an increase in oxygen affinity to $19.7 \pm 0.3$ Torr. However, $P_{50}$ remained 50fold higher than PEG- $\mathrm{Hb}^{\text {oxy }}$ under the same conditions. Cooperativity was significantly reduced, with the Hill coefficient decreasing from 2 to around 1.3. The changes in oxygen-binding properties of $T b \mathrm{Hb}$ upon PEGylation are therefore similar to those observed for PEG-Hb ${ }^{\text {oxy }}$, in particular showing loss in cooperativity. Considering the stability of the $\mathrm{TbHb}$ tetramer, this effect is likely due to the steric effects of the PEG moieties, which prevent the transition between the $T$ and $R$ states, rather than the dissociation of the tetramer, as seen in HbA. Despite the loss in cooperativity, the $P_{50}$ of PEGTbHb remains remarkably high. Moreover, ATP at saturating concentrations of $5 \mathrm{mM}$ (data not shown) still acts as an allosteric effector (Table 1), raising $P_{50}$ to 31.1 Torr. These data, combined with those relative to PEGylated Hbs of other species, particularly in bovine [30] and canine Hbs [16], show that, regardless of their different oxygen affinity, there is indeed a correlation between the increase in affinity and the PEGylation 


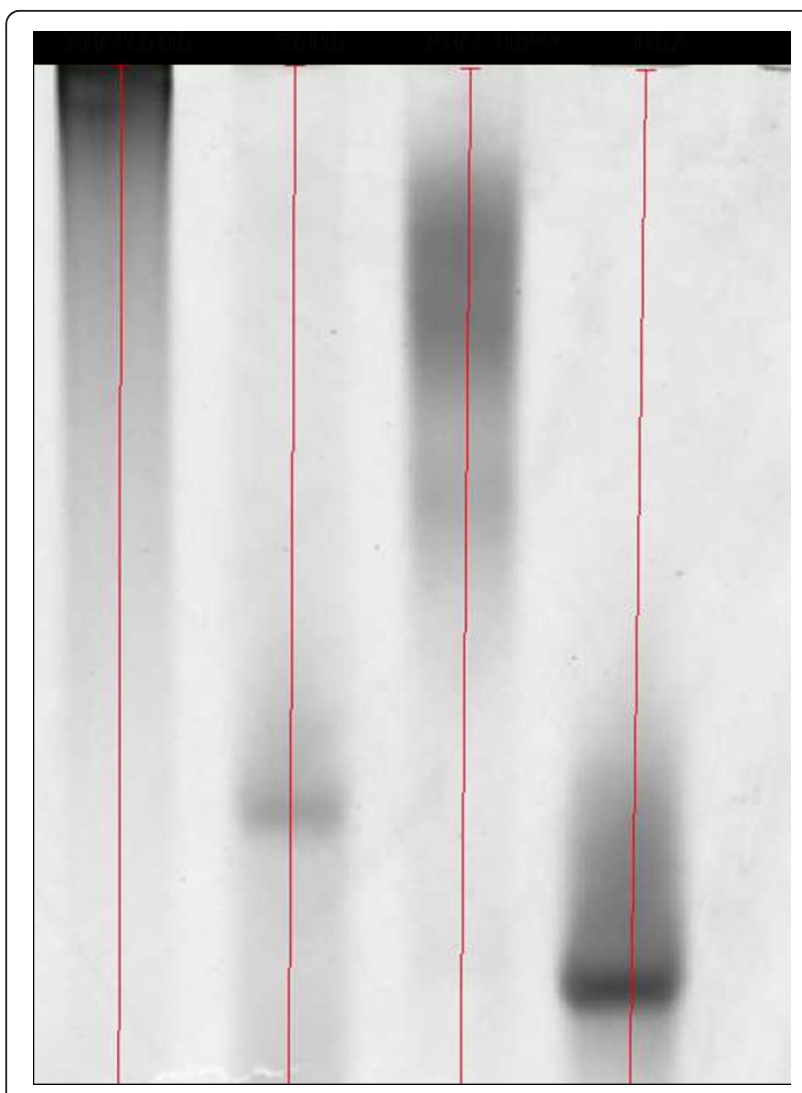

Figure 3 Size distribution of derivatized hemoglobins. Gradient native PAGE of $\mathrm{HbA}, \mathrm{TbHb}$ and their PEGylated derivatives.

reaction. The non-specific effect of PEGylation in increasing the oxygen affinity was also demonstrated within the same preparation, through the electrophoretic separation of differently PEGylated HbA derivatives having different affinities [27].

\section{Flash photolysis experiments}

The $\mathrm{CO}$ rebinding kinetics measured after laser flash photolysis on the carbomonoxy forms of $\mathrm{HbA}$ and $\mathrm{Tb} \mathrm{Hb}$ in the absence and presence of PEGylation is reported in Figure 5. The rebinding traces were converted to fraction $\mathrm{N}(\mathrm{t})$ of deoxy-Hb as a function of time. Dependence of the kinetics on the CO concentration allows distinguishing between unimolecular and bimolecular processes (data not shown). As it is well established for $\mathrm{HbA}, \mathrm{CO}$ rebinding comprises multiple phases: a nanosecond (unimolecular) geminate process due to rebinding from within the heme pocket or the protein matrix, and two second order processes, one in the microsecond time scale, ascribed to bimolecular rebinding to quaternary $\mathrm{R}$ state, and one in the millisecond time scale, ascribed to the bimolecular rebinding to proteins that have switched to quaternary $\mathrm{T}$ state [31]. In order to reproduce the experimental rebinding

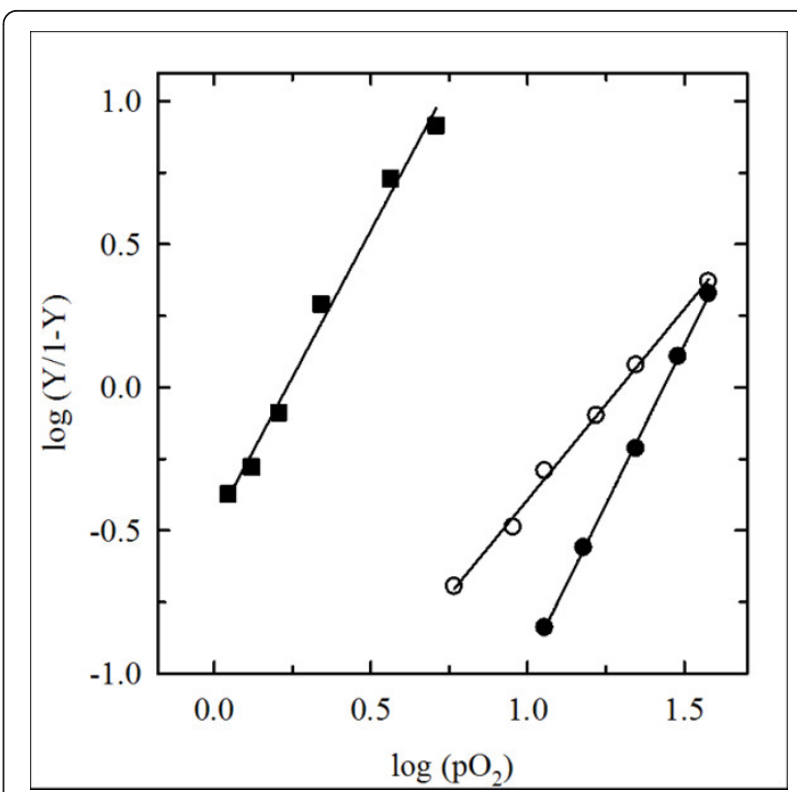

Figure 4 Oxygen binding properties of derivatized hemoglobins. Hill plots of oxygen-binding curves of $\mathrm{HbA}$ (closed squares), $\mathrm{Tb} \mathrm{Hb}$ (closed circles) and PEGTbHb (open circles),

measured in $100 \mathrm{mM}$ HEPES $1 \mathrm{mM}$ EDTA, $5 \mathrm{mM}$ sodium ascorbate, $10^{3} \mathrm{U} / \mathrm{ml}$ catalase, $\mathrm{pH} 7.0$, at $10^{\circ} \mathrm{C}$. Experimental points are fitted to the Hill equation, with calculated Hill's coefficients and $P_{50}$ 's reported in Table 1.

curves for $\mathrm{HbA}$, we used a sum of six exponential decays functions, as proposed by Kliger and coworkers [32]. In Figure 5 we also show the results of the global fitting on $\mathrm{HbA}$ and $\mathrm{Tb} \mathrm{Hb}$ (both with and without PEGylation), demonstrating a very good agreement between calculated and experimental curves. Besides the two exponential decays which are necessary for describing the geminate phase (10 and 182 ns for HbA; 14 and 452 ns for $T b \mathrm{Hb})$, we detected two processes ascribed to quaternary relaxation from the $\mathrm{R}$ to the $\mathrm{T}$ states in the micro-millisecond time scale ( 1 and $140 \mu$ s for $\mathrm{HbA}$; $110 \mu \mathrm{s}$ and $1.5 \mathrm{~ms}$ for $\mathrm{Tb} \mathrm{Hb}$ ), one phase associated with the rebinding to $\mathrm{R}$ state $(350 \mu$ s for $\mathrm{HbA} ; 7 \mathrm{~ms}$ for

Table 1 Oxygen binding parameters of human and $\mathrm{T}$. bernacchii Hbs and their PEGylated derivatives

\begin{tabular}{ccccc}
\hline & $\mathbf{p H ~ 7 . 0}$ & \multicolumn{3}{c}{$\mathbf{p H ~ 8 . 0}$} \\
\hline Protein & $\boldsymbol{P}_{\mathbf{5 0}}$ & $\mathbf{n}$ & $\boldsymbol{P}_{\mathbf{5 0}}$ & $\mathbf{n}$ \\
\hline $\mathrm{HbA}$ & $1.7 \pm 0.1$ & $2.05 \pm 0.02$ & $0.39 \pm 0.3$ & $1.72 \pm 0.03$ \\
\hline PEG-Hb & $0.4[35]$ & $1.2[36]$ & & \\
\hline TbHb & $28.2 \pm 0.2$ & $2.06 \pm 0.01$ & $7.3 \pm 0.1$ & $1.75 \pm 0.03$ \\
\hline PEGTbHb & $19.7 \pm 0.3$ & $1.33 \pm 0.02$ & $5.3 \pm 0.1$ & $1.09 \pm 0.02$ \\
\hline PEGTbHb + ATP & $31.1 \pm 0.2$ & $1.09 \pm 0.01$ & $4.4 \pm 0.3$ & $1.02 \pm 0.03$
\end{tabular}

Measurements were made in $100 \mathrm{mM}$ HEPES, $1 \mathrm{mM}$ EDTA, $5 \mathrm{mM}$ ascorbate, $10^{3} \mathrm{U} / \mathrm{ml}$ catalase, at $10^{\circ} \mathrm{C}$. The values for PEG-Hb ${ }^{\text {oxy }}$ were calculated from published data taking into account the temperature dependence of the oxygen binding parameters. 


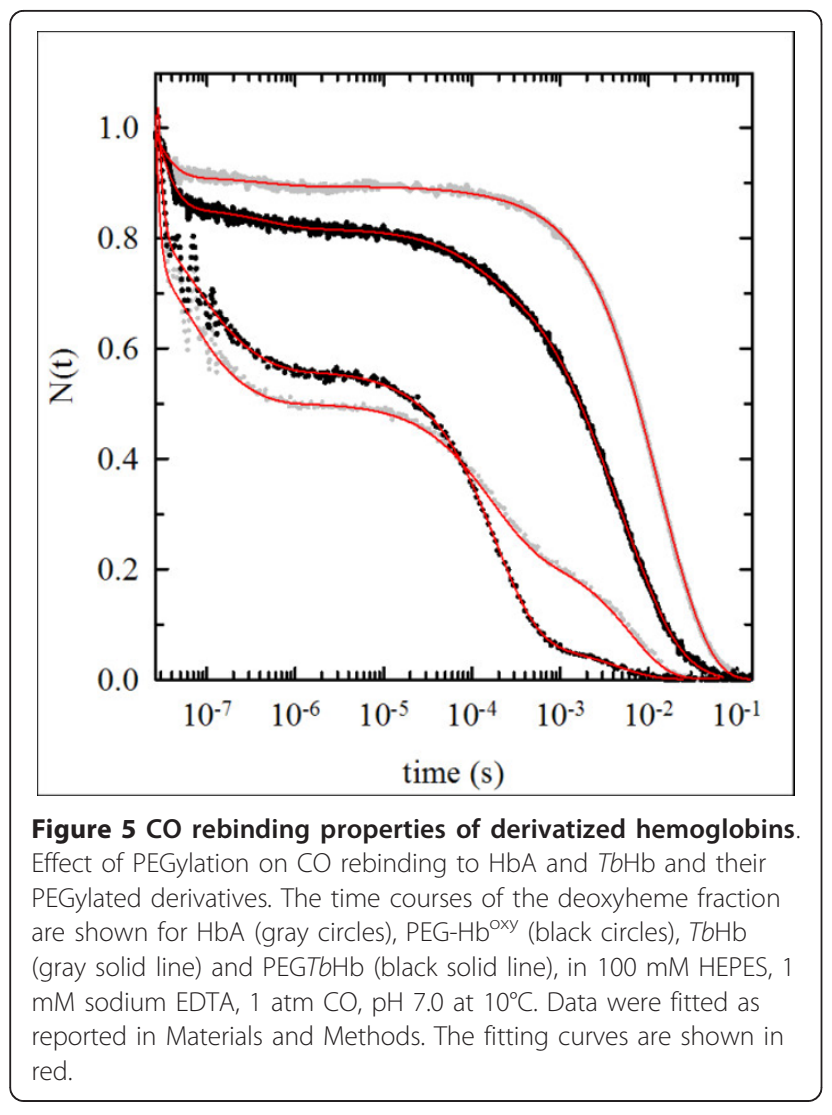

$\mathrm{Tb} \mathrm{Hb}$ ) and one phase associated with the rebinding to $\mathrm{T}$ state $(7 \mathrm{~ms}$ for $\mathrm{HbA} ; 21 \mathrm{~ms}$ for $T b \mathrm{Hb})$. As previously shown in $\mathrm{HbA}$ [11], while PEGylation preserves the general features of the dynamics and reactivity of the protein, it partially prevents the $\mathrm{R}$ to $\mathrm{T}$ relaxation, so that upon PEGylation the fractional amplitude of the rebinding to $\mathrm{R}$ changes from about $27 \%$ to $80 \%$ in $\mathrm{HbA}$ and from $34 \%$ to $76 \%$ in $\mathrm{Tb} \mathrm{Hb}$.

\section{NO dioxygenase activity}

The scavenging of NO, associated with an extremely rapid dioxygenation reaction with oxy- $\mathrm{Hb}$ to form met$\mathrm{Hb}$ and inert nitrate, is significant when $\mathrm{Hb}$ is present in blood vessels outside erythrocytes and is likely to be the main determinant of the adverse effects of HBOCs $[33,34]$. In order to develop a possible blood substitute, it is crucial to consider not only oxygen-transport properties of these Hbs, but also the influence that these products can have on NO homeostasis. The reaction rates of the NO with unmodified $T b \mathrm{Hb}$ and its PEGylated $\mathrm{Hb}$ derivatives were measured and compared with those of $\mathrm{HbA}$ and its PEGylation product. Analysis of the oxidation kinetics of oxy $\mathrm{TbHb}$ treated with $\mathrm{NO}$ (Figure 6) yields a $\mathrm{k}_{\mathrm{obs}}$ of $7.2 \mu \mathrm{M}^{-1} \mathrm{~s}^{-1}$, indicating slower reactivity with respect to $\mathrm{HbA}$, with a $\mathrm{k}_{\mathrm{obs}}$ of $64 \mu \mathrm{M}^{-1} \mathrm{~s}^{-1}$ under the same experimental conditions, in agreement

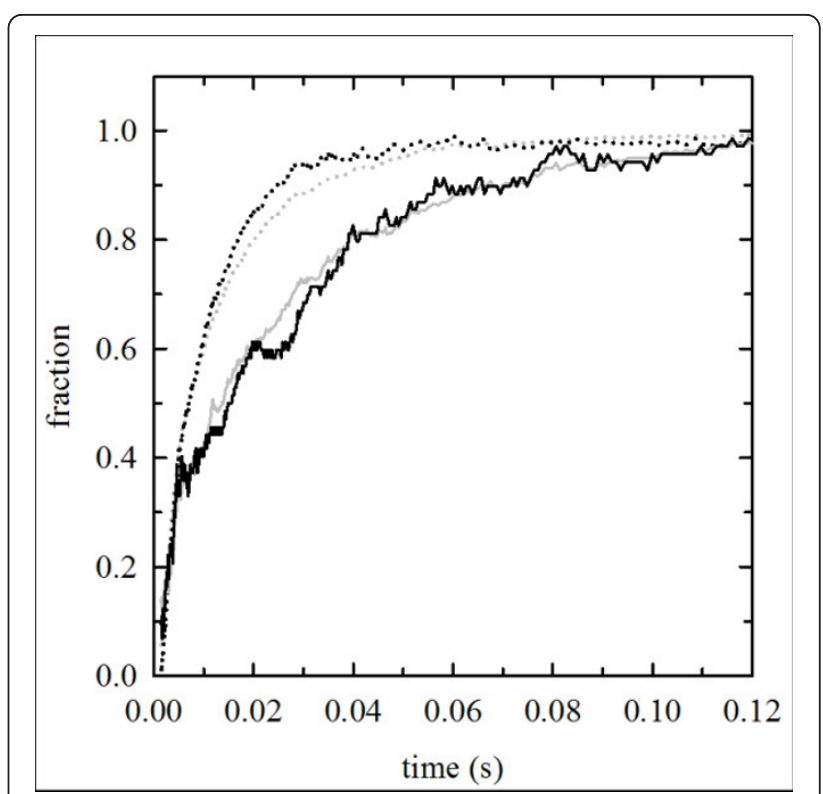

Figure 6 NO dioxygenase reactivity. Determination of the effect of PEGylation on $\mathrm{NO}$ dioxygenase reactivity of $\mathrm{HbA}$ and $\mathrm{TbHb}$ and their PEGylated derivatives. The reaction was carried out by rapid mixing under anaerobic conditions at $20^{\circ} \mathrm{C} .3 \mu \mathrm{M}$ oxygenated $\mathrm{HbA}$ (gray dotted line), $\mathrm{TbHb}$ (gray solid line), PEG-Hb ${ }^{\text {oxy }}$ (black dotted line), and PEGTbHb (black solid line), with a deoxygenated PBS solution containing $12 \mu \mathrm{M}$ NO. The reaction was monitored at 405 $\mathrm{nm}$ and absorbance differences were normalized.

with literature data [34]. PEGylation of $T b \mathrm{Hb}$ seems to only marginally affect the NO dioxygenase reactivity, with a $\mathrm{k}_{\text {obs }}$ for PEGTbHb of $7.7 \mu \mathrm{M}^{-1} \mathrm{~s}^{-1}$. A comparable decrease in the NO dioxygenase activity of $\mathrm{HbA}$ was achieved by mutating residues $\alpha \mathrm{E} 11, \beta \mathrm{E} 11$, and $\beta \mathrm{B} 10$ (2$\left.15 \mu \mathrm{M}^{-1} \mathrm{~s}^{-1}\right)$ [33]. These mutants showed reduced in vivo vasoactivity, directly correlated with the in vitro $\mathrm{NO}$ oxygenation rate. The same pattern is observed in HbA, the PEGylation of which, under aerobic and anaerobic conditions, yields $\mathrm{k}_{\mathrm{obs}}$ of $83 \mu \mathrm{M}^{-1} \mathrm{~s}^{-1}$ (Figure 6) and 86 $\mu \mathrm{M}^{-1} \mathrm{~s}^{-1}$ (data not shown), respectively.

\section{Conclusions}

The functional characterization of the PEG-conjugated derivative of the highly stable $\mathrm{Hb}$ tetramer of $T$. bernacchii confirms the non-specific effects of PEGylation already observed in human, bovine and canine Hbs, including an increase in oxygen affinity, a decrease in cooperativity and a reduction of the R-to T-quaternary switching upon flash photolysis. However, these nonspecific effects are accompanied by the partial retention of the remarkably low affinity for oxygen, the sensitivity to allosteric effectors and the low NO dioxygenase reactivity. These results indicate that PEGylated Hbs, provided that a suitable starting $\mathrm{Hb}$ variant is chosen, can cover a wide range of oxygen-binding properties, 
potentially meeting the functional requirements of blood substitutes.

\author{
Abbreviations \\ 4-PDS: 4,4'dithiodipyridine; ATP: adenosine triphosphate; EDTA: \\ ethylenediaminetetraacetic acid; HbA: human hemoglobin; HBOC: \\ hemoglobin-based oxygen carrier; IMT: 2-iminothiolane; MAL-PEG: maleimido \\ polyethylene glycol; PEG: polyethylene glycol; PBS: phosphate buffered \\ saline; SDS-PAGE: dodecylsulfate/polyacrylamide gel electrophoresis; $\mathrm{TbHb}$ : \\ Trematomus bernacchii hemoglobin.
}

\section{Acknowledgements}

This study is financially supported by the Italian National Programme for Antarctic Research (PNRA) and Fondazione Cariparma (to AM), and is in the framework of the SCAR programme Evolution and Biodiversity in the Antarctic (EBA) and the project CAREX (Coordination Action for Research Activities on Life in Extreme Environments), European Commission FP7 call ENV.2007.2.2.1.6.

This project was supported by the Italian Ministero dell'Istruzione, dell'Università e della Ricerca (MIUR), Direzione Generale per I'Internazionalizzazione della Ricerca, Progetti di Grande Rilevanza Italia-Argentina. We are grateful to Prof. Lelio Mazzarella for invaluable discussion, ideas and enthusiastic support in addressing these themes.

\section{Author details}

${ }^{1}$ Institute of Protein Biochemistry, CNR, Naples, Italy. ${ }^{2}$ Department of Biochemistry and Molecular Biology, University of Parma, Parma, Italy. ${ }^{3}$ Department of Physics, University of Parma, NEST Istituto Nanoscienze-CNR, Parma, Italy. ${ }^{4}$ Department of Biotechnology, University of Verona, Verona, Italy.

\section{Authors' contributions}

GdP initiated this investigation by collecting material from cold-adapted fish in Antarctica. DC, CiV and GdP purified T. bernacchii Hb. DC and LR performed $\mathrm{Hb}$ PEGylation and electrophoretic characterization, DC and SB investigated oxygen binding and performed cysteyl titrations. SB characterized NO dioxygenase reactivity and wrote the manuscript, CrV and SA performed the flash photolysis experiments. AM contributed to the manuscript preparation. All authors read and approved the final manuscript.

Received: 26 July 2011 Accepted: 20 December 2011

Published: 20 December 2011

\section{References}

1. Faggiano S, Bruno S, Ronda L, Pizzonia P, Pioselli B, Mozzarelli A: Modulation of expression and polymerization of hemoglobin Polytaur, a potential blood substitute. Arch Biochem Biophys 2011, 505:42-47.

2. Fronticelli C, Koehler RC: Design of recombinant hemoglobins for use in transfusion fluids. Crit Care Clin 2009, 25:357-371.

3. Fronticelli C, Koehler RC, Brinigar WS: Recombinant hemoglobins as artificial oxygen carriers. Artif Cells Blood Substit Immobil Biotechnol 2007, 35:45-52.

4. Bobofchak KM, Mito T, Texel SJ, Bellelli A, Nemoto M, Traystman RJ, Koehler RC, Brinigar WS, Fronticelli C: A recombinant polymeric hemoglobin with conformational, functional, and physiological characteristics of an in vivo $\mathrm{O} 2$ transporter. Am J Physiol Heart Circ Physiol 2003, 285:H549-561.

5. Panetta G, Arcovito A, Morea V, Bellelli A, Miele AE: Hb(alphaalpha, betabeta): a novel fusion construct for a dimeric, four-domain hemoglobin. Biochim Biophys Acta 2008, 1784:1462-1470.

6. Ronda L, Bruno S, Abbruzzetti S, Viappiani C, Bettati S: Ligand reactivity and allosteric regulation of hemoglobin-based oxygen carriers. Biochim Biophys Acta 2008, 1784:1365-1377.

7. Vandegriff KD, Malavalli A, Wooldridge J, Lohman J, Winslow RM: MP4, a new nonvasoactive PEG-Hb conjugate. Transfusion 2003, 43:509-516.

8. lafelice R, Cristoni S, Caccia D, Russo R, Rossi-Bernardi L, Lowe KC, Perrella M: Identification of the sites of deoxyhaemoglobin PEGylation. Biochem J 2007, 403:189-196.
9. Winslow RM: Cell-free oxygen carriers: scientific foundations, clinical development, and new directions. Biochim Biophys Acta 2008, 1784:1382-1386.

10. Natanson C, Kern SJ, Lurie P, Banks SM, Wolfe SM: Cell-free hemoglobinbased blood substitutes and risk of myocardial infarction and death: a meta-analysis. Jama 2008, 299:2304-2312.

11. Caccia D, Ronda L, Frassi R, Perrella M, Del Favero E, Bruno S, Pioselli B, Abbruzzetti S, Viappiani C, Mozzarelli A: PEGylation promotes hemoglobin tetramer dissociation. Bioconjug Chem 2009, 20:1356-1366.

12. Reischl E, Dafre AL, Franco JL, Wilhelm Filho D: Distribution, adaptation and physiological meaning of thiols from vertebrate hemoglobins. Comp Biochem Physiol C Toxicol Pharmacol 2007, 146:22-53.

13. Manjula BN, Tsai A, Upadhya R, Perumalsamy K, Smith PK, Malavalli A, Vandegriff K, Winslow RM, Intaglietta M, Prabhakaran M, et al: Site-specific PEGylation of hemoglobin at Cys-93(beta): correlation between the colligative properties of the PEGylated protein and the length of the conjugated PEG chain. Bioconjug Chem 2003, 14:464-472.

14. Li D, Hu T, Manjula BN, Acharya SA: Extension arm facilitated pegylation of alphaalpha-hemoglobin with modifications targeted exclusively to amino groups: functional and structural advantages of free Cys-93(beta) in the PEG-Hb adduct. Bioconjug Chem 2009, 20:2062-2070.

15. Li D, Manjula BN, Ho NT, Simplaceanu V, Ho C, Acharya AS: Molecular aspects of the high oxygen affinity of non-hypertensive hexa pegylated hemoglobin, [(SP-PEG5K)(6)-Hb]. Artif Cells Blood Substit Immobil Biotechnol 2007, 35:19-29.

16. Acharya SA, Acharya VN, Kanika ND, Tsai AG, Intaglietta M, Manjula BN: Non-hypertensive tetraPEGylated canine haemoglobin: correlation between PEGylation, $\mathrm{O} 2$ affinity and tissue oxygenation. Biochem J 2007, 405:503-511.

17. Winslow RM, Gonzales A, Gonzales ML, Magde M, McCarthy M, Rohlfs RJ, Vandegriff KD: Vascular resistance and the efficacy of red cell substitutes in a rat hemorrhage model. J Appl Physiol 1998, 85:993-1003.

18. di Prisco G, Eastman JT, Giordano D, Parisi E, Verde C: Biogeography and adaptation of Notothenioid fish: hemoglobin function and globin-gene evolution. Gene 2007, 398:143-155.

19. Giangiacomo L, D'Avino R, di Prisco G, Chiancone E: Hemoglobin of the Antarctic fishes Trematomus bernacchii and Trematomus newnesi: structural basis for the increased stability of the liganded tetramer relative to human hemoglobin. Biochemistry 2001, 40:3062-3068.

20. Mazzarella L, Vergara A, Vitagliano L, Merlino A, Bonomi G, Scala S, Verde C, di Prisco G: High resolution crystal structure of deoxy hemoglobin from Trematomus bernacchii at different $\mathrm{pH}$ values: the role of histidine residues in modulating the strength of the root effect. Proteins 2006, 65:490-498.

21. Hayashi A, Suzuki T, Shin M: An enzymic reduction system for metmyoglobin and methemoglobin, and its application to functional studies of oxygen carriers. Biochim Biophys Acta 1973, 310:309-316.

22. D'Avino R, Di Prisco G: Antarctic fish hemoglobin: an outline of the molecular structure and oxygen binding properties-I. Molecular structure. Comp Biochem Physiol, B 1988, 90:579-584.

23. Camardella L, Caruso C, D'Avino R, di Prisco G, Rutigliano B, Tamburrini M, Fermi G, Perutz MF: Haemoglobin of the antarctic fish Pagothenia bernacchii. Amino acid sequence, oxygen equilibria and crystal structure of its carbonmonoxy derivative. J Mol Biol 1992, 224:449-460.

24. Ronda L, Bruno S, Faggiano S, Bettati S, Mozzarelli A: Oxygen binding to heme proteins in solution, encapsulated in silica gels, and in the crystalline state. Methods Enzymol 2008, 437:311-328.

25. Ainsworth S, Treffry A: A study of the properties of two porphyringlobin species formed in the reaction of protoporphyrin IX with human globin. Biochem J 1974, 137:331-337.

26. Winslow RM: MP4, a new nonvasoactive polyethylene glycol-hemoglobin conjugate. Artif Organs 2004, 28:800-806.

27. Ronda L, Pioselli B, Bruno S, Faggiano S, Mozzarelli A: Electrophoretic analysis of PEGylated hemoglobin-based blood substitutes. Anal Biochem 2011, 408:118-123.

28. Abbruzzetti S, Bruno S, Faggiano S, Grandi E, Mozzarelli A, Viappiani C: Time-resolved methods in Biophysics. 2. Monitoring haem proteins at work with nanosecond laser flash photolysis. Photochem Photobiol Sci 2006, 5:1109-1120.

29. Bruno S, Faggiano S, Spyrakis F, Mozzarelli A, Abbruzzetti S, Grandi E, Viappiani C, Feis A, Mackowiak S, Smulevich G, et al: The reactivity with CO 
of $\mathrm{AHb} 1$ and $\mathrm{AHb} 2$ from Arabidopsis thaliana is controlled by the distal HisE7 and internal hydrophobic cavities. J Am Chem Soc 2007, 129:2880-2889.

30. Vandegriff KD, McCarthy M, Rohlfs RJ, Winslow RM: Colloid osmotic properties of modified hemoglobins: chemically cross-linked versus polyethylene glycol surface-conjugated. Biophys Chem 1997, 69:23-30.

31. Henry ER, Jones CM, Hofrichter J, Eaton WA: Can a two-state MWC allosteric model explain hemoglobin kinetics? Biochemistry 1997, 36:6511-6528.

32. Goldbeck RA, Paquette SJ, Bjorling SC, Kliger DS: Allosteric intermediates in hemoglobin. 2. Kinetic modeling of HbCO photolysis. Biochemistry 1996, 35:8628-8639.

33. Doherty DH, Doyle MP, Curry SR, Vali RJ, Fattor TJ, Olson JS, Lemon DD: Rate of reaction with nitric oxide determines the hypertensive effect of cell-free hemoglobin. Nat Biotechnol 1998, 16:672-676.

34. Eich RF, Li T, Lemon DD, Doherty DH, Curry SR, Aitken JF, Mathews AJ, Johnson KA, Smith RD, Phillips GN Jr, Olson JS: Mechanism of NO-induced oxidation of myoglobin and hemoglobin. Biochemistry 1996, 35:6976-6983.

35. Samaja M, Melotti D, Rovida E, Rossi-Bernardi L: Effect of temperature on the p50 value for human blood. Clin Chem 1983, 29:110-114.

36. Portoro I, Kocsis L, Herman P, Caccia D, Perrella M, Ronda L, Bruno S, Bettati S, Micalella C, Mozzarelli A, et al: Towards a novel haemoglobinbased oxygen carrier: Euro-PEG-Hb, physico-chemical properties, vasoactivity and renal filtration. Biochim Biophys Acta 2008, 1784:1402-1409.

doi:10.1186/1471-2091-12-66

Cite this article as: Coppola et al: Low affinity PEGylated hemoglobin from Trematomus bernacchii, a model for hemoglobin-based blood substitutes. BMC Biochemistry 2011 12:66.

\section{Submit your next manuscript to BioMed Central} and take full advantage of:

- Convenient online submission

- Thorough peer review

- No space constraints or color figure charges

- Immediate publication on acceptance

- Inclusion in PubMed, CAS, Scopus and Google Scholar

- Research which is freely available for redistribution

Submit your manuscript at www.biomedcentral.com/submit
Biomed Central 